\title{
Solution to quality assurance challenge 11
}

\author{
Manfred Reichenbächer • Jürgen W. Einax
}

(C) Springer-Verlag Berlin Heidelberg 2013

\section{Solution}

Query A: Check the mean values in the pre-period for normal distribution and outliers

First, the mean values $\bar{x}_{j}$ of the $i$ observations measured for $j$ levels in the pre-period listed in Table 1 must be checked for normal distribution and outliers [1-3].

The test value $\widehat{q}_{r}=2.804$ calculated according to Eq. (1)

$\widehat{q}_{r}=\frac{\bar{x}_{\max }-\bar{x}_{\min }}{s}$

with $\bar{x}_{i, \max }=0.1577, \bar{x}_{i, \min }=0.1527$ and $s=0.00178$ lies within the critical limits 2.67 and 3.685 of the David table for $P=95 \%$ and $n=10$ ( Table A-8 in Ref. [1]). Therefore, the mean values of the data can be assumed to be normally distributed.

The check for an outlier $x^{*}$ must be performed by use of the Dixon outlier test. The test value $\widehat{Q}$ is calculated for $n=$ 10 observations by use of Eq. (2)

$\widehat{Q}=\left|\frac{\bar{x}_{1}^{*}-\bar{x}_{2}}{\bar{x}_{1}^{*}-\bar{x}_{n-1}}\right|$

in which $\bar{x}$ and $\bar{x}_{2}$ are the second highest and second smallest values, respectively, and $n$ is the magnitude of the data set $[1,3]$.

The intermediate quantities and results are given in Table 2 . The test values $\widehat{Q}$ are smaller than the critical limit

This article is the solution to the Analytical Challenge which can be found at http://dx.doi.org/10.1007/s00216-012-6632-0

M. Reichenbächer · J. W. Einax $(\bowtie)$

Institute of Inorganic and Analytical Chemistry,

Friedrich Schiller University Jena, Lessingstraße 8,

07734 Jena, Germany

e-mail: juergen.einax@uni-jena.de
$Q(P=95 \% ; n=10)=0.477$ (Table A-7 in Ref. [1]), meaning the data set is free of outliers. Therefore, the whole data set can be used for construction of the control charts.

Query B: Shewhart chart for monitoring the mean values and determining whether the analytical system is under control

The upper and lower action lines (UAL and LAL, respectively), and the upper and lower warning limit lines (UWL and LWL, respectively) of the Shewhart control chart are calculated by use of the equations:

For the warning limit lines,

$\bar{x} \pm 2 s$

and for the action limit lines

$\bar{x} \pm 3 s$

Because replicates were performed, the standard deviation $s$ must be determined by use of the variance components $s_{b w}^{2}$ and $s_{i n}^{2}$ in accordance with Eq. (5) (p. 289 in Ref. [1]).

$s=\sqrt{s_{b w}^{2}+\frac{s_{i n}^{2}}{s_{b w}^{2}}}$.

The variance components are calculated by analysis of variance, ANOVA [1, 4].

$s_{b w}^{2}=\frac{S S_{b w}}{d f_{b w}}$

$s_{\text {in }}^{2}=\frac{S S_{\text {in }}}{d f_{\text {in }}}$. 
Table 1 Analytical results and intermediate quantities of the $i$ observations for determination of nitrite nitrogen in the pre-period

\begin{tabular}{|c|c|c|c|c|c|c|c|c|c|c|c|}
\hline No. & $c_{i}\left(\mathrm{mg} \mathrm{L}^{-1}\right)$ & $\bar{x}_{j}$ & $x_{i, \max }$ & $x_{i, \min }$ & $R_{i}$ & No. & $c_{i}\left(\mathrm{mg} \mathrm{L}^{-1}\right)$ & $\bar{x}_{j}$ & $x_{i, \max }$ & $x_{i, \text { min }}$ & $R_{i}$ \\
\hline \multirow[t]{3}{*}{1} & $\begin{array}{l}0.152 \\
0.153\end{array}$ & \multirow[t]{3}{*}{0.1527} & \multirow[t]{3}{*}{0.153} & \multirow[t]{3}{*}{0.152} & \multirow[t]{3}{*}{0.001} & \multirow[t]{3}{*}{6} & 0.152 & \multirow[t]{3}{*}{0.1537} & \multirow[t]{3}{*}{0.155} & \multirow[t]{3}{*}{0.152} & \multirow[t]{3}{*}{0.003} \\
\hline & 0.153 & & & & & & 0.155 & & & & \\
\hline & 0.153 & & & & & & 0.154 & & & & \\
\hline \multirow[t]{3}{*}{2} & 0.156 & \multirow[t]{3}{*}{0.1550} & \multirow[t]{3}{*}{0.156} & \multirow[t]{3}{*}{0.154} & \multirow[t]{3}{*}{0.002} & \multirow[t]{3}{*}{7} & 0.158 & \multirow[t]{3}{*}{0.1573} & \multirow[t]{3}{*}{0.158} & \multirow[t]{3}{*}{0.156} & \multirow[t]{3}{*}{0.002} \\
\hline & 0.154 & & & & & & 0.156 & & & & \\
\hline & 0.155 & & & & & & 0.158 & & & & \\
\hline \multirow[t]{3}{*}{3} & 0.151 & \multirow[t]{3}{*}{0.1540} & \multirow[t]{3}{*}{0.156} & \multirow[t]{3}{*}{0.151} & \multirow[t]{3}{*}{0.005} & \multirow[t]{3}{*}{8} & 0.153 & \multirow[t]{3}{*}{0.1530} & \multirow[t]{3}{*}{0.154} & \multirow[t]{3}{*}{0.152} & \multirow[t]{3}{*}{0.002} \\
\hline & 0.156 & & & & & & 0.154 & & & & \\
\hline & 0.155 & & & & & & 0.152 & & & & \\
\hline \multirow[t]{3}{*}{4} & 0.161 & \multirow[t]{3}{*}{0.1577} & \multirow[t]{3}{*}{0.161} & \multirow[t]{3}{*}{0.156} & \multirow[t]{3}{*}{0.005} & 9 & 0.156 & 0.1563 & 0.158 & 0.155 & 0.003 \\
\hline & 0.156 & & & & & & 0.158 & & & & \\
\hline & 0.156 & & & & & & 0.155 & & & & \\
\hline 5 & 0.154 & 0.1537 & 0.154 & 0.153 & 0.001 & 10 & 0.153 & 0.1540 & 0.155 & 0.153 & 0.002 \\
\hline & 0.153 & & & & & & 0.155 & & & & \\
\hline & 0.154 & & & & & & 0.154 & & & & \\
\hline
\end{tabular}

The degrees of freedom $d f_{b w}$ and $d f_{i n}$ are given by Eqs. (8) and (9), respectively:

$d f_{b w}=n_{i}-1$

$d f_{\text {in }}=n_{j} \cdot n_{i}-n_{i}$

in which the observation number $n_{i}$ is 10 and the replicate number $n_{j}$ is 3 .

Table 2 Intermediate quantities and results of the Dixon outlier test on the highest $\left(\bar{x}_{\max }\right)$ and smallest $\left(\bar{x}_{\min }\right)$ mean values obtained during the pre-period

\begin{tabular}{lllll}
\hline Test value & $\bar{x}_{1}^{*}$ & $\bar{x}_{2}$ & $\bar{x}_{n-1}$ & $\widehat{Q}$ \\
\hline $\bar{x}_{\max }$ & 0.1577 & 0.1573 & 0.1530 & 0.085 \\
$\bar{x}_{\min }$ & 0.1527 & 0.1530 & 0.1573 & 0.065 \\
\hline
\end{tabular}

Table 3 Intermediate quantities and results from ANOVA $(\overline{\bar{x}}=0.1547)$

\begin{tabular}{llrr}
\hline Observation no. & $\bar{x}_{j}$ & $10^{6} n_{j}\left(\bar{x}_{j}-\overline{\bar{x}}\right)^{2}$ & $10^{6} S S_{j}$ \\
\hline 1 & 0.1527 & 12.813 & 0.667 \\
2 & 0.1550 & 0.213 & 2.000 \\
3 & 0.1540 & 1.613 & 14.000 \\
4 & 0.1577 & 25.813 & 16.667 \\
5 & 0.1537 & 3.413 & 0.667 \\
6 & 0.1537 & 3.413 & 4.667 \\
7 & 0.1573 & 20.280 & 2.667 \\
8 & 0.1530 & 9.013 & 2.000 \\
9 & 0.1563 & 7.680 & 4.667 \\
10 & 0.1540 & 1.613 & 2.000 \\
Sum & & 85.867 & 50.00 \\
\hline
\end{tabular}

The sums of squares $S S_{b w}$ and $S S_{i n}$ are calculated by use of Eq. (11) and (10), respectively:

$S S_{b w}=\sum n j\left(\bar{x}_{j}-\overline{\bar{x}}\right)^{2}$

$S S_{\text {in }}=\sum S S_{j}$

The results of ANOVA are obtained by use of the intermediate quantities listed in Table 3:

$\overline{\bar{x}}=0.15473, S S_{b w}=0.0000859, S S_{j}=S S_{i n}=0.0000500$, $d f_{b w}=9, d f_{i n}=20, s_{b w}^{2}=0.00000954$, and $s_{i n}^{2}=0.00000250$.

The standard deviation $s$, calculated by use of Eq. (5), is $s=0.00322 \mathrm{mg} \mathrm{L}^{-1}$.

Now, the Shewhart control chart can be constructed by use of the following data set:

$\overline{\bar{x}}=0.15473 \mathrm{mg} \mathrm{L}^{-1}, \mathrm{UAL}=0.1644 \mathrm{mg} \mathrm{L}^{-1}, \mathrm{UWL}=$ $0.1612 \mathrm{mg} \mathrm{L}^{-1}, \mathrm{LWL}=0.1483 \mathrm{mg} \mathrm{L}^{-1}, \mathrm{LAL}=0.1451 \mathrm{mg} \mathrm{L}^{-1}$.

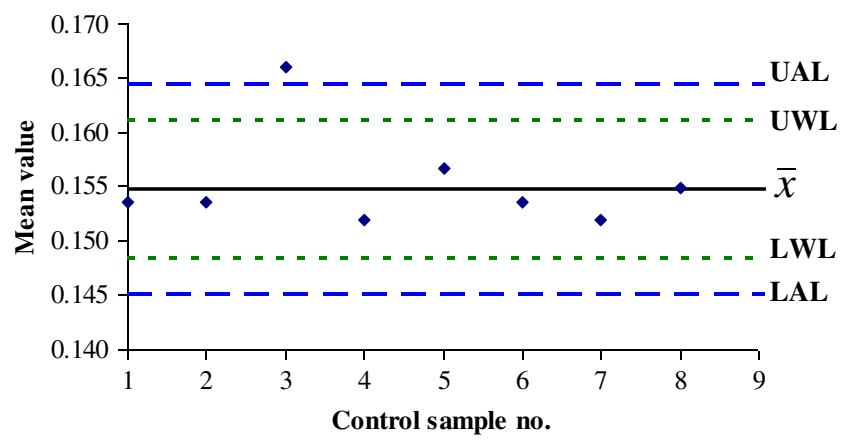

Fig. 1 Shewhart chart for monitoring the mean value (recognition of bias) 
Table 4 Mean values of the first eight analytical results obtained by use of an in-house reference material for routine analysis

\begin{tabular}{|c|c|c|c|c|c|c|c|c|c|}
\hline No. & $c_{i}\left(\mathrm{mg} \mathrm{L}^{-1}\right)$ & $x_{i, \max }$ & $x_{i, \min }$ & $R_{i}$ & No. & $c_{i}\left(\mathrm{mg} \mathrm{L}^{-1}\right)$ & $x_{i, \max }$ & $x_{i, \min }$ & $R_{i}$ \\
\hline \multirow[t]{2}{*}{1} & $\begin{array}{l}0.154 \\
0.152\end{array}$ & \multirow[t]{2}{*}{0.155} & \multirow[t]{2}{*}{0.152} & \multirow[t]{2}{*}{0.154} & \multirow[t]{2}{*}{5} & $\begin{array}{l}0.158 \\
0.155\end{array}$ & \multirow[t]{2}{*}{0.158} & \multirow[t]{2}{*}{0.155} & \multirow[t]{2}{*}{0.157} \\
\hline & 0.155 & & & & & 0.157 & & & \\
\hline \multirow[t]{2}{*}{2} & $\begin{array}{l}0.152 \\
0.154\end{array}$ & \multirow[t]{2}{*}{0.155} & \multirow[t]{2}{*}{0.152} & \multirow[t]{2}{*}{0.154} & \multirow[t]{2}{*}{6} & $\begin{array}{l}0.151 \\
0.158\end{array}$ & \multirow[t]{2}{*}{0.158} & \multirow[t]{2}{*}{0.151} & \multirow[t]{2}{*}{0.154} \\
\hline & 0.155 & & & & & 0.152 & & & \\
\hline \multirow[t]{2}{*}{3} & $\begin{array}{l}0.164 \\
0.168\end{array}$ & \multirow[t]{2}{*}{0.168} & \multirow[t]{2}{*}{0.164} & \multirow[t]{2}{*}{0.166} & \multirow[t]{2}{*}{7} & $\begin{array}{l}0.151 \\
0.153\end{array}$ & \multirow[t]{2}{*}{0.153} & \multirow[t]{2}{*}{0.151} & \multirow[t]{2}{*}{0.152} \\
\hline & 0.166 & & & & & 0.152 & & & \\
\hline \multirow[t]{2}{*}{4} & $\begin{array}{l}0.150 \\
0.152\end{array}$ & \multirow[t]{2}{*}{0.154} & \multirow[t]{2}{*}{0.15} & \multirow[t]{2}{*}{0.152} & \multirow[t]{2}{*}{8} & $\begin{array}{l}0.154 \\
0.155\end{array}$ & \multirow[t]{2}{*}{0.156} & \multirow[t]{2}{*}{0.154} & \multirow[t]{2}{*}{0.155} \\
\hline & 0.154 & & & & & 0.156 & & & \\
\hline
\end{tabular}

The Shewhart control chart constructed by use of these data, the result of quality control during routine analysis of the first analytical results obtained by use of an in-house reference material, is presented in Fig. 1. The mean values are listed in Table 4.

Inspection of Fig. 1 reveals an out-of-control situation at observation no. 3. This mean value lies beyond the upper action line. After correction of the problem, the analytical system is again under control, as revealed by the measured values for the next observation. Note that the Shewhart control chart can also be used to identify the trend of an analytical method where a trend exists; here, however, no trend can be recognized.

\section{Query C: Chart for monitoring the precision and determining whether homogeneity of variances applies}

Whereas the Shewhart control chart is best used for detecting bias in an analytical system, the range chart is used for monitoring analytical precision. The range chart is based on the range values obtained in the pre-period, given

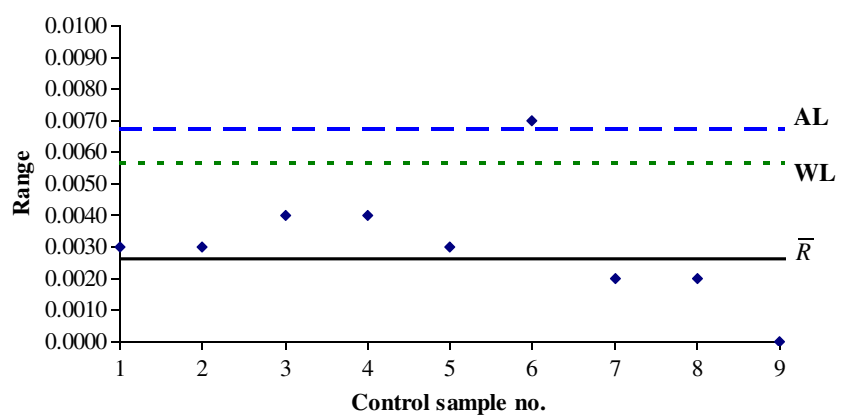

Fig. 2 Range chart for controlling precision during routine analysis in Table 1. The limiting values of the range chart are calculated by use of the following equations:

Warning limit lines WL:

$W L=\bar{R} \cdot D_{W L}$

Action limit lines AL:

$A L=\bar{R} \cdot D_{A L}$

The average range $\bar{R}$ is calculated by use of

$\bar{R}=\frac{\sum R_{i}}{n}$

in which $n$ is the number of observations (in this example $n=10$ ) and the ranges $R_{i}$ of all sub-groups must be determined according to:

$R_{i}=x_{i, \max }-x_{i, \min }$.

The $D$-factors for $n_{j}=3$ given in Table 8.2-1 of Ref. [1] are $D_{W L}=2.176$ and $D_{A L}=2.575$.

The limiting values of the range chart calculated by use of the intermediates given in Table 1 and the mean value $\bar{R}=0.0026$ are $\mathrm{AL}=0.00670 \mathrm{mg} \mathrm{L}^{-1}$, and $\mathrm{WL}=$ $0.00566 \mathrm{mg} \mathrm{L}^{-1}$.

The range chart for the first eight observations in routine analysis is shown in Fig. 2. Observation reveals an out-of-control situation for no. 6 , because the range value lies outside the action line. After removal of the cause, e.g. exchanging the HPLC injection syringe, the analytical system is again under control. 
Thus, use of a combination of a mean value chart and a range chart is appropriate for checking the bias and precision, and the homogeneity of variances in the analytical system.

Note that the intermediate quantities given above were calculated by use of Excel functions; therefore, calculation using the values given in the tables might cause some small numerical deviations.

\section{References}

1. Reichenbächer M, Einax JW (2011) Challenges in analytical quality assurance, Springer Heidelberg, and references cited therein

2. Reichenbächer M, Einax JW (2006) Anal Bioanal Chem 384: 14

3. Reichenbächer M, Einax JW (2006) Anal Bioanal Chem 385: 792

4. Reichenbächer M, Einax JW (2005) Anal Bioanal Chem 383:3-5 